\title{
Article \\ Improving Technological Infrastructure of Distance Education through Trustworthy Platform-Independent Virtual Software Application Pools
}

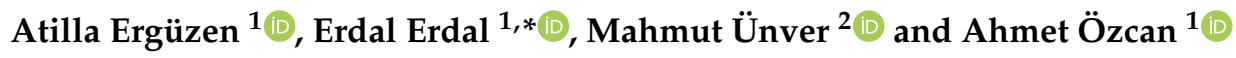 \\ 1 Department of Computer Engineering, Faculty of Engineering and Architecture, Kırıkkale University, \\ Kırıkkale 71450, Turkey; atilla@kku.edu.tr (A.E.); aozcan@kku.edu.tr (A.Ö.) \\ 2 Department of Computer Programming, Kırıkkale Vocational School, Kırıkkale University, \\ Kırıkkale 71450, Turkey; munver@kku.edu.tr \\ * Correspondence: erdalerdal@kku.edu.tr; Tel.: +90-318-357-4242-1549
}

Citation: Ergüzen, A.; Erdal, E.; Ünver, M.; Özcan, A. Improving Technological Infrastructure of Distance Education through Trustworthy Platform-Independent Virtual Software Application Pools. Appl. Sci. 2021, 11, 1214. https:// doi.org/10.3390/app11031214

Academic Editor: Antonio

Sarasa Cabezuelo

Received: 21 December 2020

Accepted: 21 January 2021

Published: 28 January 2021

Publisher's Note: MDPI stays neutral with regard to jurisdictional claims in published maps and institutional affiliations.

Copyright: (c) 2021 by the authors. Licensee MDPI, Basel, Switzerland. This article is an open access article distributed under the terms and conditions of the Creative Commons Attribution (CC BY) license (https:// creativecommons.org/licenses/by/ $4.0 /)$.

\begin{abstract}
Distance education (DE), which has evolved under the wings of information technologies in the last decade, has become a fundamental part of our modern education system. DE has not only replaced the traditional education method as in social sciences and lifelong learning opportunities but also has significantly strengthened traditional education in mathematics, science, and engineering fields that require practical and intensive study. However, it is deprived of supporting some key elements found in traditional educational approaches such as (i) modern computer laboratories with installed special software suitable for the student's field of interest; (ii) adequate staff for maintenance and proper functioning of laboratories; (iii) face-to-face technical support; (iv) license fees. For students to overcome these shortcomings, a virtual application pool is needed where they can easily access all the necessary applications via remote access. This research aims to develop a platformindependent virtual laboratory environment for DE students. This article has been developed specifically to guide DE institutions and to make a positive contribution to the literature. Technology Acceptance Model (TAM) has been used to explain student behaviors. It was concluded that students using the platform performed more successful grades (12.89\%) on laboratory assessments and that the students using the developed platform were found to be more satisfied with the education process.
\end{abstract}

Keywords: education; engineering education; laboratory; distance learning

\section{Introduction}

With the rapid developments in Information and Communication Technology (ICT) and internet usage over the last decade, significant changes have occurred in every aspect of people's lives [1]. The contribution of the internet to these developments is undoubtedly very important. Thanks to these technological developments and the changes, it has been possible to access the internet cheaper than in the past [2]. The use of the internet has become widespread and has begun to affect people in all aspects. According to the Turkish Statistical Institute (TSI), 76.3\% of households in Turkey had internet access in 2016. When the ratio of the number of mobile phone population in Turkey is considered, $96.9 \%$ of people were found to have a mobile phone. In total, $65.2 \%$ of people with the internet connection at home prefer smartphones and tablets for daily routines, such as surfing, sending e-mails, connecting to news sites, and social networks [3].

Although computers have been used very often, nowadays this situation has completely changed; mobile devices, smartphones, and tablets have become widespread and indispensable. Tablets or tablet computers are small independent mobile computers that house a thin LCD monitor and provide data entry and data control via this screen. They are usually preferred for their powerful hardware, portable dimensions, internet connections, and all the other functions they have. These critical innovations have also affected the 
policies of the countries, in this way, Increasing Opportunities and Improving Technology (IOIT) Project was launched in 2016 in Turkey. This project aims to provide the best education for each student, to reach the best quality education contents, and to provide equality of opportunity in education so it is reported that 10,600,000 tablets will be distributed by the Ministry of National Education within the period of the next 4 years [4]. Table 1 shows the device sales worldwide in recent years and the number of devices expected to take place in the following years. Demand and sales of mobile devices that take place in Turkey show similarities with the numbers worldwide [5].

Table 1. Worldwide device shipments by device type, 2016-2019 (millions of units) [5].

\begin{tabular}{ccccc}
\hline Device Type & $\mathbf{2 0 1 6}$ & $\mathbf{2 0 1 7}$ & $\mathbf{2 0 1 8}$ & $\mathbf{2 0 1 9}$ \\
\hline Traditional PCs (desk-based and notebook) & 220 & 204 & 195 & 188 \\
Ultra-mobiles (premium) & 50 & 59 & 70 & 80 \\
Total PC market & 270 & 263 & 265 & 269 \\
Ultra-mobiles (basic and utility) & 169 & 162 & 161 & 160 \\
Computing devices market & 439 & 425 & 426 & 429 \\
Mobile phones & 1893 & 1882 & 1926 & 1932 \\
Total devices market & 2332 & 2307 & 2352 & 2361 \\
\hline
\end{tabular}

Consequently, a critical question arises regarding how mobile devices will affect people's habits, lifestyles, and educational concepts. Today, students use their smartphones and tablets at all stages of their education, regardless of class or age. Distance education (DE) has become a phenomenon worldwide, with universities offering distance learning programs in the light of the developments that have changed people's lifestyles and technology infrastructure, and it has become possible for people to study more than one field without the time and space limitation [6,7].

DE is a virtual educational approach in which it accommodates multiple training models. DE provides more flexible lecture management models that are based on synchronous or asynchronous courses. There is also a lot of work in the literature to attract the attention of the learners and to make DE more interactive. A distance educational approach is preferred where the traditional teaching and learning methods are inadequate or inappropriate. The distance, capacity, and educational deficiencies found in the traditional education model can be overcome with the DE model. Especially, in countries where economic opportunities and cross-cultural understanding are limited, a distance educational approach could be a good choice for economic solutions and online cross-cultural learning activities also [6-8].

Traditional DE has been adopted as an attractive and preferred method of education all over the world. In each educational year, the number of students who attend the DE model increases by $5 \%$ approximately. The Massachusetts Institute of Technology (MIT) has reached more than 200 million page clicks on 2300 different distance learning courses in the 2016/2017 academic year [9]. A total of 360,000 foreign students are studying at Harvard University in this way [10]. All these indications are that the distance learning method is accepted by prominent universities and that it will be a future phenomenon in the field of education.

Just as in the world, Turkey is also impressed by this trend and DE has started to become popular. As of 2013, over 60 academic departments via DE in Turkey are provided by universities at undergraduate and graduate levels. All these opportunities have facilitated to access the desired educational environment, so this increasing demand leads to an e-learning sector in Turkey. This sector is expected to exceed USD 240 billion between 2016 and 2023 with an annual growth rate of 5\% nearly while the world is USD 164 billion in 2015 [11].

Despite all these benefits and advantages, in some areas where DE is applied, it lacks some of the basic supporting elements found in formal education. The applicability of DE is not especially productive in fields were specially designed large-scale application software 
or laboratory environment practice is a mandatory requirement in engineering education. There are virtual or remote laboratory designs that are proven to be very versatile and valuable especially for the students in Science, Technology, and Engineering (STE) fields which is a necessity to develop laboratory exercises to supplement the theoretical lectures. Additionally, there are studies in the literature, which are developed based on a specific lecture in different fields $[12,13]$. These laboratories have the following advantages [12]:

- Usability: laboratories can be accessed at anytime from anywhere.

- Observability: laboratories can be monitored and recorded by more than one person.

- Accessibility: laboratories can also be used by people with disabilities.

- Safety: dangerous experiments can be done safely.

However, the benefits and deficiencies of any developed technological design or application should be addressed objectively. The Technology Acceptance Model which explains the intentions of consumers is used to undertake necessary research in evaluating the efficiency of the system developed [14,15]. TAM is a theory of information systems that model how students use and adopt the technology. TAM is one of the widely used models for describing the factors that have the greatest influence on user acceptance of information systems. Davis (1989) developed TAM to explain the effects of user perceptions of system factors that are thought to be effective on users' acceptance of information systems. TAM is the most widely used modeling approach in information systems models. The reason for this is that TAM is understandable and easy to apply. TAM contains two key factors as shown in Figure 1. These are perceived usefulness (PU) and perceived ease of use (PEU) [16].

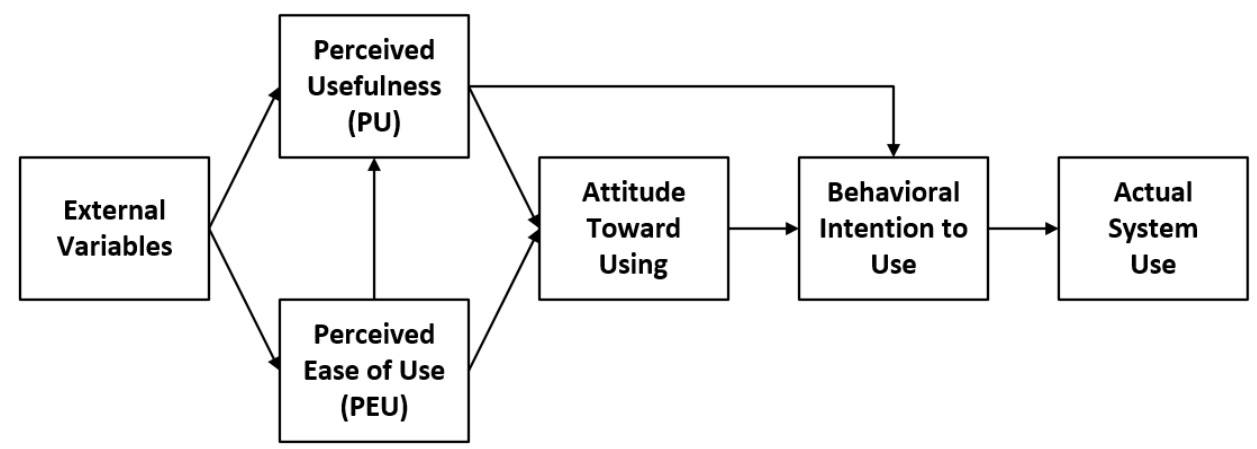

Figure 1. Technology Acceptance Model (TAM).

PU and PEU are very significant in defining the usage and acceptance of information technologies. Davis (1989) defines these two factors as important that shape the intentions of individuals in using information systems [16].

These two variables play the main role in determining the attitudes of individuals who use information technology systems. Davis (1989) describes the PEU of technology as easy to learn, and that the use of this technology can be effortlessly learned. Many empirical studies have provided strong evidence that PU directly affects personal intentions in the context of new technology. Conversely, the effects of PU are more controversial and are not simply defined as PEU's effects [16].

In literature, studies have generally been based on evaluating students' learning outcomes, satisfaction, and even the effectiveness of virtual or remote laboratories according to their educational background even studies identifying the prerequisite analysis to recognize the needs and possibilities to integrate new technologies and methods for lab-based learning in the field of Industry 4.0 and the Internet of Things $[12,13,17,18]$. However, according to our knowledge, there is no virtual or remote laboratory model in the literature, this is the key point of this study. In this study, a platform-independent virtual laboratory system suitable for computers, smartphones, and tablets has been developed for DE students in information technology. Our motivation for developing this platform is to provide a better education level through institutional plans and processes. With the help of the 
security layer that contains student-specific information and security measures, students have access to developed platforms and lecture materials shared by the lecturers in the laboratory. The developed platform is still being used by Kırıkkale University Distance Education Center. To assess the success of the developed platform, two random groups of 43 students were used which is the limitation of the study. Traditional DE training and assignments were defined to the first group and traditional DE training and developed laboratory platform were opened to access to the second group. Both groups were given the same lectures and the same assignments for 4 weeks. At the end of this period, one final homework was given to both groups and their success rates were compared. Besides, the TAM was used to explain the student behaviors of the developed laboratory system. At the end of the study, it was concluded that students using the platform performed $12.89 \%$ more successful grades and that the students using the developed platform were more satisfied when the satisfaction surveys were compared. At the end of this work, a Strengths, Weaknesses, Opportunities, Threats (SWOT) analysis was presented to identify gaps in the developed system and suggest possible ways to resolve the defects. In this study, the deficiencies in the literature were solved, the literature on the state-of-the-art approach was contributed by a better and effective method, and a basic study was undertaken which bridges the gap in the literature.

\section{Literature Review}

It is imperative to apply and implement technology-driven systems to achieve quality learning processes in information technology and engineering education. Laboratory experiments are needed to increase professional skills, create professional practices, develop analytical concepts, and ensure student participation at the highest level, in fact, studies that verify the versatile benefits of laboratory facilities for engineering students are available in the literature [19]. Students can easily run the software installed on the server as if it were installed on their computers on the browser. Especially expensive, difficult to install software that requires expensive hardware features that are installed on the server and made available to students on the internet. Thus, students can access expensive software labs from anywhere and whenever they want without going to school. These laboratories have crucial educational tools that allow students to access real interfaces and tools as if they were physically in the laboratory. However, there are also difficulties and barriers to be overcome as defined below, as well as the advantages of the developed virtual or remote laboratories.

The first and the most important problem encountered in the virtual and distance learning laboratories developed is that the control systems and physical equipment cannot be seamlessly integrated into the laboratories. This area uses server-client, 3-tier architecture, and standards for laboratory systems applied to different areas. These kinds of laboratories in the literature can address a specific subject or lecture and also on behavioral, cognitive, affective, and cognitive learning outcomes in higher education [20,21]. The developed approach that is appropriate for the curriculum is presented which is to enhance the overall student laboratory experience.

Another challenge in this area is creating or updating the educational content in the laboratory. The maintenance and management of the developed laboratory are giving the system administrator additional responsibility. As the number of simulations and physical systems involved in the laboratory increases, it is difficult for system administrators to control the whole system and control its contents. The solution to this problem in the literature is the CMS, Content Management System, tools that make it possible to support the platform more easily and to manage it more effectively [22]. However, the management and maintenance of the CMS also cause problems in this manner. In the laboratory approach, we developed in this study, the system administrator is only in charge of introducing students and instructors to the system. All additional materials and files used in the laboratory are copied to the personal folders of the students when they are added to the system by the teaching staff. In other words, the students who are attending 
distance learning in the field of information technology and engineering can instantly view the materials added to their folders by the instructor when they access the system.

Another key problem with this area is that the developed laboratories are dependent on the computer resources used by the students and continuance intention [18,23]. Interfaces, simulations, and online systems that take the resources of student computers depend on the characteristics of these computers, thus affecting the quality of education. In the laboratory approach that we developed in this study, all necessary system requirements and resources are provided by the servers. In this way, students can access all laboratory facilities of good quality and fast at any time and place. Regardless of the capacity of the student computer, all students are given server resources equally. This criterion is one of the most important elements of our study.

Another problem that arises is the phase in which students install software on their personal computers. Software development tools are used in laboratories especially in information technology and engineering education. Students in distance learning in this area need to install software on their personal computers that will be used to access the lab facilities. However, this installation requires experience, time, and extreme license costs, and even sensor technologies with developing technology [24]. Due to these difficulties, students cannot install the tools that they need on their personal computers. The developed laboratory in this study is based on the principle of hosting all necessary software on the servers and running one click without any cost. In this way, students have access to the necessary memories of without any difficulty.

The next obstacle is due to the nature of DE. Students can perceive this education as a video game because they think that this system is virtual, not actual. This prediction is accompanied by the lack of attention and the lack of responsibility and seriousness of the students, however, despite all its shortcomings, DE is defined as a never-ending education model. In order for this never-ending education model to be more efficient, it is stated that virtual environments should be used [17]. In the proposed laboratory approach, the students can listen to the lecturer's narration at the same time and work instantly in the laboratory environment which is one of the strengths of this study. Besides, thanks to note-based follow-up objects such as paper and homework that are given by the lecturer, students can approach the system seriously and responsibly. Teachers can guide students through virtual lesson tools. In this way, students can learn which applications to do in the virtual laboratory, understand how to do it, and receive sample codes. Thus, maximum interaction is provided between the student and the teacher in the laboratory environment.

As a result, the laboratory solutions developed for the DE system have some deficiencies and issues that need to be improved. A lot of work has been done in this area and solutions have been produced; however, there is still no complete solution in the literature. When the solutions are examined, it is seen that problems such as integration, educational content management, student computer resource usage, license problem, and experience required installation or attention deficiencies of students are found. The reason for these problems is due to the nature of traditional DE or the lack of developed solutions. In this study, the laboratory environment required for information technology and engineering education was improved by eliminating the deficiencies in the literature. Primary features of the developed exclusive platform are listed; (a) suitable architecture for multiple-courses, (b) license-free for applications, (c) no need for installation, (d) platform-independent usage, (e) regardless of user's computer performance, (f) easy-to-learn content updates and insertion, $(\mathrm{g})$ encouraging learning through the integration of laboratory experiment and lecture at the same time. In this context, the developed information technology and the remote education laboratory applied in the field of engineering are bridging the gap in the literature. 


\section{Materials and Methods}

\subsection{General Background}

The scope of this work is the development of the laboratory environment needed by DE students in information technology. The research was conducted in the 2017/2018 academic year spring semester for five weeks using software assignments on the web programming lecture. For five weeks, two groups of 43 people were randomly assigned to the distance learning courses in information technology and engineering. Group 2, which has the same traditional DE as Group 1, also used a newly developed laboratory platform in the laboratory experience. In the study, four assignments were given to both groups thus student habits were formed on both systems. In the fifth week, a final assessment was given to students and the results of all the assignments were compared. Assignments have the following features:

- In the web programming course, students can design and program dynamic web pages over the asp.net platform.

- Homework was determined according to the topics of the current week which includes page design and coding.

- All communication with students and teachers was carried out via the current LMS. Therefore, the assignments were sent to the students, and tracking was done through this platform.

- The same homework was given to each group, but students were asked to solve them individually.

- After the assignments were determined, 4 days was given and finally received over the active LMS.

- Assignments were evaluated by other professors who are experts on the subject.

The success of the groups in the comparison was statistically analyzed. Besides, a questionnaire based on the TAM was conducted in Group 2, which was trained using the developed laboratory. This questionnaire was analyzed with the Likert scale to get more consistent results.

\subsection{Motivation}

The developed system is suitable for the use of all branches of science that need software in the laboratory. All software installed on the server can be made available to students for all engineering fields.

\subsection{Design Achievements}

A web-based remote laboratory implementation for engineering education has been improved. The developed laboratory system architecture is as shown in Figure 2. It provides students with easy access from inside and outside of the campus. In this way, students can use the laboratory system where and when they want it. However, students who want to access the laboratory system from outside the university campus can access this system through the remote desktop gateway server. Otherwise, the firewall located on the campus will not allow access to the laboratory system. The students can use the same system as on campus by using the username and password information given to them. The students can use the same system as on campus by using the username and password information given to them, a Virtual Private Network (VPN) that is defined in [25]. Platform-independent development allows students to use the system with smartphones, tablets, laptops, or desktop computers.

Universities have know-how in distance education. For this reason, the proposed system is one of the areas and applications that students mostly demand and need. Software and hardware costs are high in countries generally. For this reason, it is difficult for students to cover the license costs and use of up-to-date software. Therefore, it was a necessity to present all software to the students through the system developed.

In the scope of this work: 
1. The developed system was integrated to the current LMS for students to log into the system directly;

2. In addition, a log module was developed where all the work is recorded, especially the entrance/exit of all students, is recorded;

3. The VPN layer was added to the system infrastructure only as an extra security layer;

4. The laboratory software required by the students according to their departments was integrated into the system. In this way, the following benefits were obtained;

i. Without paying license costs;

ii. Without installation on their own computers;

iii. Providing students with weak computers without any disruption and using server power for all transactions;

iv. Live laboratory application environment integrated with virtual classroom was developed. In this way, students and lecturers can use software such as in the real classroom and laboratory environment.

5. There are solutions close to this solution in the market. However, these solutions are not fully integrated into distance education and are solutions with high license costs. We developed this system on servers, which are our university's own resources, and integrated with LMS.

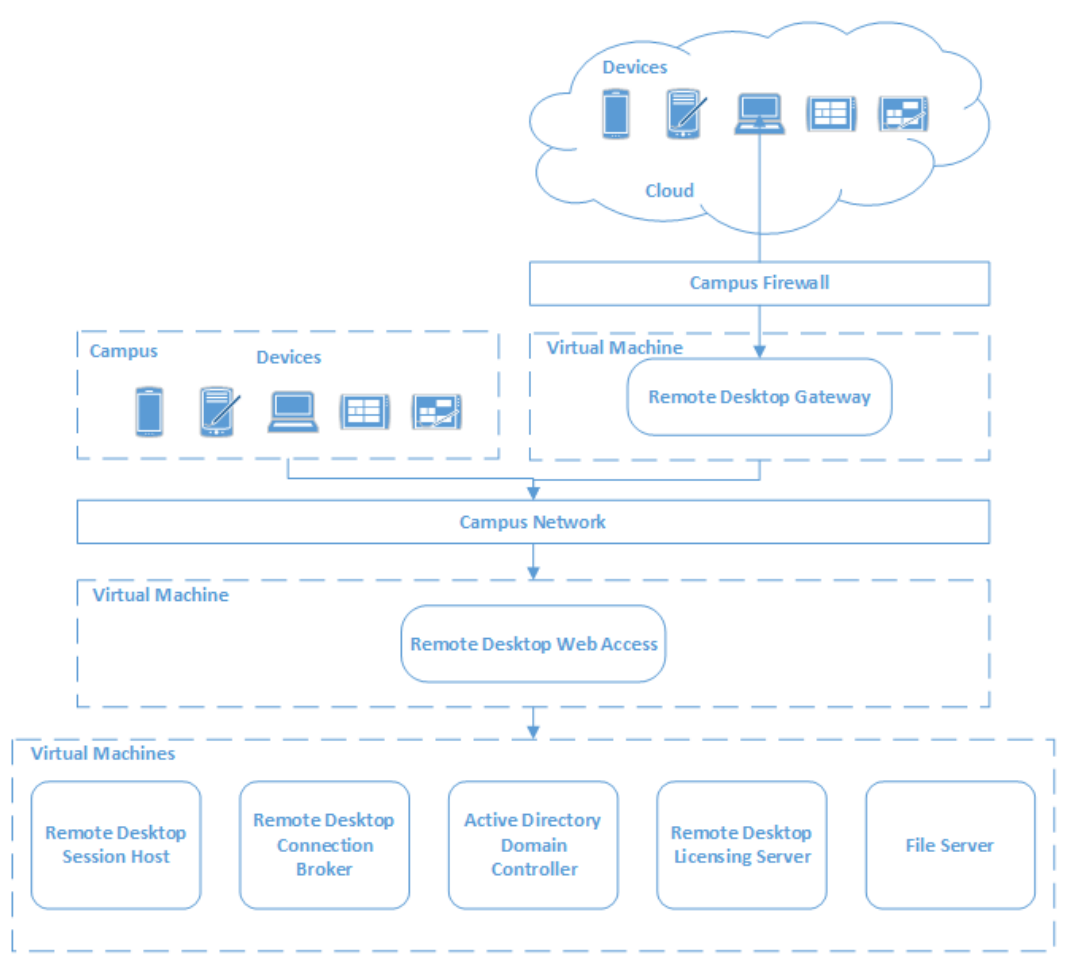

Figure 2. System architecture.

Students in the campus network can access the user login screen on the virtual desktop by typing in the internet browsers. The login screen, which welcomes the students who want to use the laboratory system, is in this virtual server. At this stage, the username and password information given is requested from the students and the user authentication is done through the active directory domain controller virtual machine according to [26]. This authentication server also contains primary information about students. In this way, class information of the students is taken, and the appropriate and defined programs are presented to the students for their curriculum. Students can open and use the software they want to study by clicking on the program link from the programs listed. It is the Remote Desktop Session Host virtual server where the session information is generated by the system after the students' authentication and all the programs and software presented 
to the students are hosted and executed. In case the number of students or the number of programs and software needs to increase, adding a new Remote Desktop Session Host virtual server to the architecture is enough to meet this need described in [27]. The developed laboratory system is designed in a scalable and modular structure. A file server was created to prevent overloading of the system and to work with the files that students produced as a result of their work and shared by the academic staff as in [28]. All files in the system are configured to be hosted on this file server. All licenses used in the laboratory system with some basic license requirements are hosted in the Remote Desktop Licensing virtual server defined in [27]. In this way, it is possible to perform transactions without needing to interfere with other licensed virtual servers in case of a possible license requirement, renewal, or failure. A load balancing mechanism was also added to the architecture to avoid problems such as interruptions, faults, and speed loss in the laboratory system and to operate the system efficiently as in [29]. Load balancing operations are performed via the remote desktop connection broker virtual server defined in (Hannifin et al., 2010). Additionally, an architectural role-based design proposed in the developed laboratory system and a role diagram are presented in Figure 3.

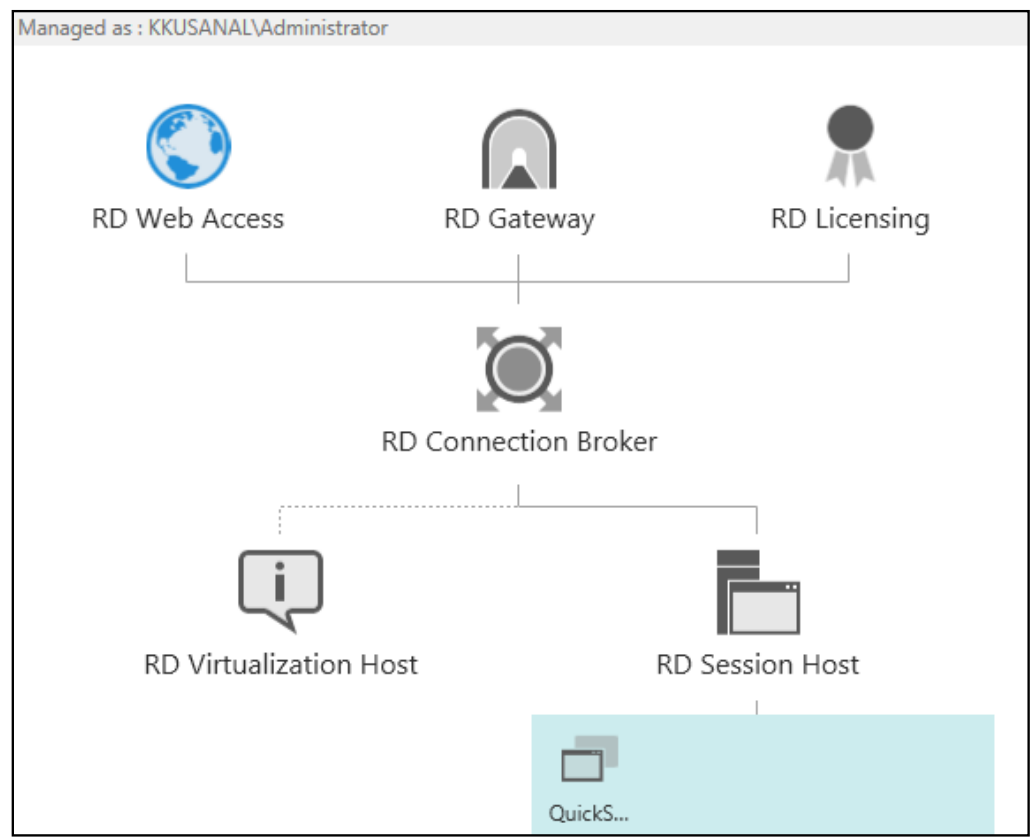

Figure 3. Laboratory system role schemes.

Thanks to the developed laboratory system students are provided access to this system regardless of location and time without costs such as license, installation, and speed. In this way, students can easily use expensive and specialized laboratories from wherever they are, every day of the week. Thus, the cost of establishing and operating large laboratories within institutions is greatly reduced.

\subsection{Research Participants}

The evaluation of the developed laboratory system was carried out through the web programming lesson homework given in the 2017 / 2018 academic year spring semester. The students who participated in the evaluation were randomly divided into two groups.

Lectures and assignments were given to $43(\mathrm{~N}=43)$ students in the first group through traditional DE. In the second group, $43(\mathrm{~N}=43)$ students were given lectures via traditional $\mathrm{DE}$, and assignments were given through the developed laboratory system. A total of $86(\mathrm{~N}=86)$ students studying in the same academic program were selected to evaluate the system from Kirıkkale University that has more than 35,000 students. With average annual university graduation of 6000 students, more than 7000 young students come to the 
university each year. To evaluate the developed laboratory system, all the students in the relevant school agreed to use the system and complete the questionnaires.

\subsection{Instrument and Procedures}

Three different questionnaires were applied to the groups that were established to evaluate the developed laboratory system. In the first part of the questionnaire, students were asked about their demographic information. With this survey, demographic information such as age, gender, level of income, and professional experience related to the participants were analyzed. In the second part, the final assignments given by 86 students $(\mathrm{N}=86)$ were read and graded by the academic staff. The first comparison of the performance of the laboratory system on students' assignments was evaluated. In the last part of the questionnaire, 39 questions consisting of five Likert measurement systems including perceived usefulness, perceived ease of use, attitude, intention, and actual behaviors for information technology usage were asked in the second group, and students who used this system during the course. All the questionnaire forms were included in the analysis and the SPSS 22 computer program was used to analyze the survey results.

\subsection{Experimental Setup}

To evaluate the developed infrastructure, the "web programming" course, in which the number of students is slightly higher, was determined. Students were randomly divided into two groups. Group 1 continued to receive training with classical laboratory methods as in previous years. Group 2 used the newly developed laboratory infrastructure as part of the study. However, promotional activities and demo activities were carried out about the new system developed for students to have more consistent and precise views.

Afterwards, five different pieces of homework in 5 weeks were attended to by students during the academic year. The grades of the students were evaluated and recorded by independent instructors.

The obtained values were analyzed by statistical methods. Additionally, questionnaires were applied to learn the perspectives of the students on the developed system and to examine its acceptability. The values obtained as a result of the surveys were also analyzed by statistical methods. All the steps are shown in Figure 4 below.

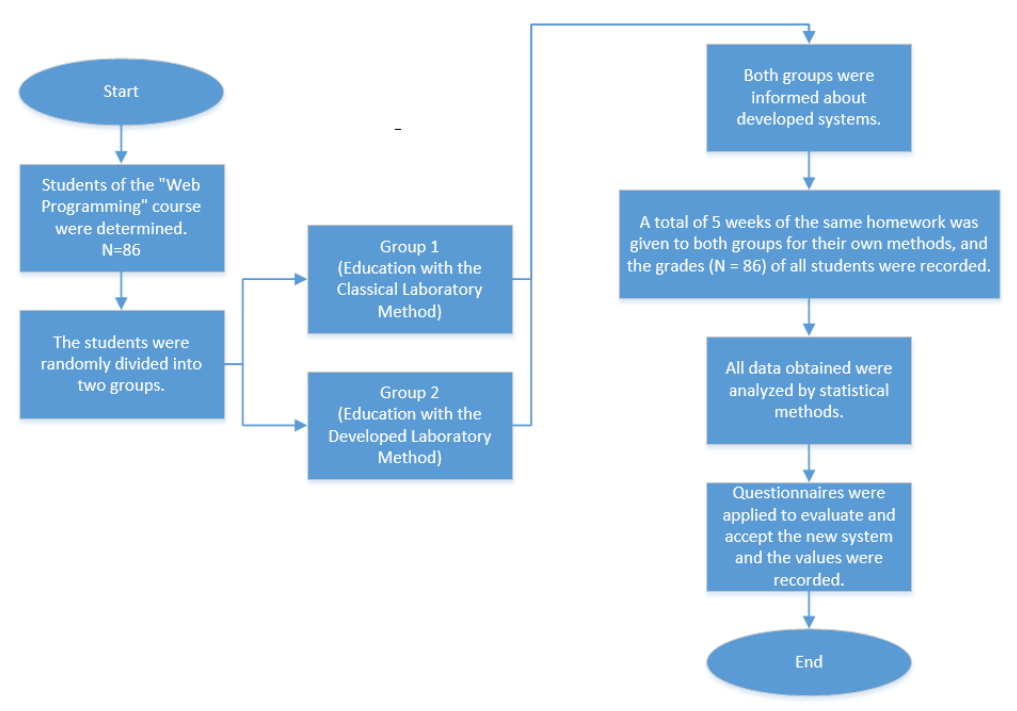

Figure 4. Detailed data collecting process flowchart.

\section{Data Analysis}

\subsection{Questionnaire 1: Demographic Profiles}

The demographic information of the students participating in the questionnaire is given in Table 2. 
Table 2. Demographic information of the attendances.

\begin{tabular}{cccc}
\hline Variable & Variable Levels & N & Percentage (\%) \\
\hline \multirow{3}{*}{ Age } & $16-26$ & 53 & 61.62 \\
& $27-37$ & 27 & 31.41 \\
& $38-48$ & 4 & 4.67 \\
Gender & 49 and over & 2 & 2.32 \\
& Male & 78 & 90.69 \\
& Female & 8 & 9.30 \\
\hline \multirow{2}{*}{ Income rate } & TRY 750 and less & 14 & 16.27 \\
& TRY 751-TRY 1500 & 32 & 37.20 \\
& TRY 1501-TRY 2250 & 23 & 26.74 \\
& TRY 2251-TRY 3000 & 12 & 13.95 \\
& TRY 3000 and over & 5 & 5.81 \\
\hline \multirow{2}{*}{ Professional } & 1-3 years & 68 & 79.06 \\
experience & 4-6 years & 14 & 16.27 \\
& 7 year and over & 4 & 4.65 \\
\hline
\end{tabular}

According to Table $2,61.62 \%$ of the participants had a range of $16-26,31.41 \%$ had $27-37,4.67 \%$ had $38-48$, and $2.32 \%$ had 49 years of age and above. A total of $90.69 \%$ of the respondents were male, $9.31 \%$ were female. In total, $16.27 \%$ of the participants have an income of $750 \mathrm{TL}$ or less, $37.20 \%$ have an income between TRY 751 and TRY 1500, 26.74\% have an income between TRY 1501 and TRY 2250, 13.95\% is between TRY 2251 and TRY 3000 , and $5.81 \%$ have TRY 3000 and above. A total of $79.06 \%$ of the participants have 1-3 years, $16.27 \% 4-6$ years, and $4.65 \% 7$ years and above professional experience.

\subsection{Questionnaire 2: Impact of Developed System on Student Assignments}

The effects of the developed system on student assignments grade were also measured. DE students in the field of information technology were divided into two groups. The same software assignments were given to both groups for 5 weeks in web programming. While the first group created all the assignments for the traditional DE approach, the second group created all the assignments through the new laboratory system. To read all the assignments belonging to both groups, information technology and engineering staff in charge of teaching were determined. To read all the assignments belonging to both groups, independent information technology, and engineering staff were determined. All assignments from students were randomly mixed and read by independent instructors. Independent lecturers were asked to evaluate all assignments over 100 points. Besides, Group 1 students traditionally attended $2 \mathrm{~h}$ of weekly laboratory lessons, but Group 2 students spent $27.89 \%$ more time in the online laboratory system than Group 1 students. The average of all grades belonging to the groups is shown in Table 3 for each week.

Table 3. Group and week based results of software assignments.

\begin{tabular}{|c|c|c|c|c|}
\hline Week & Assignment & Subject & Group $1(N=43)$ & Group $2(N=43)$ \\
\hline 1 & 1 & HTML Basics & 67.41 & 65.54 \\
\hline 2 & 2 & CSS Basics & 72.23 & 74.69 \\
\hline 3 & 3 & $\begin{array}{c}\text { Javascript } \\
\text { Fundamentals }\end{array}$ & 71.78 & 79.23 \\
\hline 4 & 4 & $\begin{array}{l}\text { C\#.NET Basic Web } \\
\text { Components }\end{array}$ & 64.12 & 80.49 \\
\hline \multirow[t]{2}{*}{5} & Final assignment & $\begin{array}{c}\text { Designing a Static } \\
\text { Web Page }\end{array}$ & 69.71 & 82.60 \\
\hline & Mean & & 69.05 & 76.51 \\
\hline
\end{tabular}


The subjects that students will learn within the scope of the determined course each week were determined in advance in the curriculum. Table 3 contains the topics covered in the course each week. Each week after the lesson, the instructor defined an assignment for the students. Group 1 was asked to complete the homework in the laboratory hour of the lesson, as in the classical education teaching model. However, the students in Group 2 completed their assignment using the newly developed system. Assignments were evaluated by a different professor weekly, but the results were collectively explained to the students at the end of the 5 th week.

As seen in Table 3, there is a difference of 12.89 (18.49\%) between final assignments and $16.46(10.80 \%)$ by the average of all weeks. It was found that the group that the system was applied to performed more successfully than the weekly and the final assignment. The graph for the better evaluation and observation of the separately obtained values is shown in Figure 5.

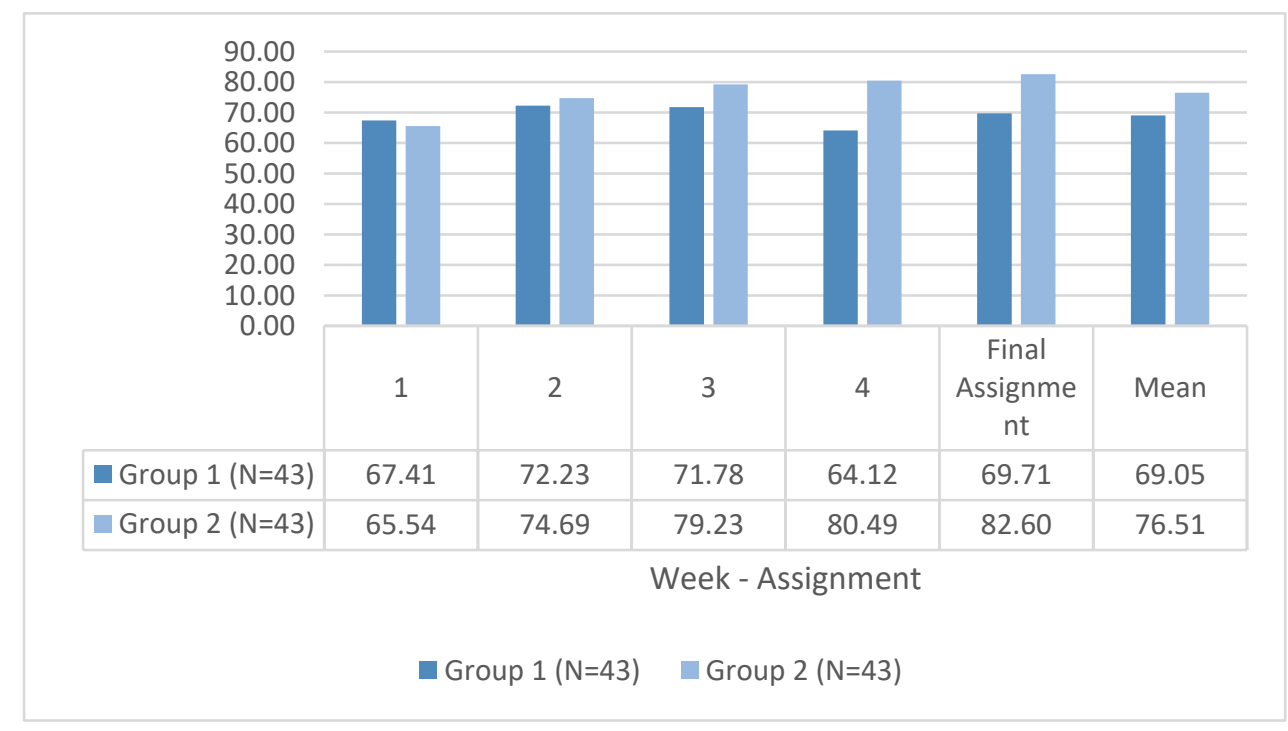

Figure 5. Week-assignment group note distribution.

\subsection{Questionnaire 3: Technology Acceptance Model}

The research model used at this stage of the study is the classical TAM shown in Figure 1 [14,16]. In the questionnaire, 13 questions about the perceived benefit for use of information technology, 13 questions about perceived ease of use, four questions about attitude change, seven questions about intention change, and two questions about measuring last behavior variable were asked.

The materials in the measurement tool were derived from the work of [19]. In responding to the survey tool, the situations described by the materials are arranged as "Totally Participating", "Partly Participating", "Participating", "Poorly Participating", and "Neither Participating". The measurement tool was arranged according to the factors and the average of the responses taken from the students in response to the answers listed in the form, provided in Table 4.

Besides, all students were informed in detail about the newly developed system before the surveys. Besides, demo sessions were held for 2 weeks for both groups to get used to the systems.

In terms of perceived use and intention in Table 4 , it is seen that the average is generally over four points. Four values correspond to the expression "I agree" on the scale. Accordingly, it can be said that the perceived usefulness and intentions of the participants to use information technology products are high. 
From the point of view of perceived ease of use, the highest arithmetic average (4.54) stands out as "I can easily do what I want to do with my lesson thanks to the new laboratory system".

Table 4. Mean and standard deviation values of TAM components.

\begin{tabular}{|c|c|c|c|}
\hline & Expressions & Mean & Standard Deviation \\
\hline \multirow{13}{*}{ Perceived Ease } & Using the new laboratory system makes my lessons and assignments easier & 4.55 & 0.947 \\
\hline & Using the new laboratory system increases my mastery of the lecture & 4.43 & 0.927 \\
\hline & Using the new laboratory system improves performance in the classroom & 4.46 & 0.813 \\
\hline & Using the new laboratory system meets my classroom needs & 4.32 & 0.959 \\
\hline & Using the new laboratory system saves me time & 4.57 & 0.692 \\
\hline & Using the new laboratory system allows me to perform tasks faster & 4.58 & 0.532 \\
\hline & Using the new laboratory system provide support for important issues in the classroom & 4.31 & 0.663 \\
\hline & Using the new laboratory system, I can do more work & 4.56 & 0.667 \\
\hline & Using the new laboratory system reduces the amount of time I spend on unnecessary work & 4.42 & 0.712 \\
\hline & Using the new laboratory system increases productivity in the classroom & 4.56 & 0.781 \\
\hline & Using the new laboratory system increases the quality of my work & 4.12 & 0.928 \\
\hline & Using the new laboratory system improves the efficiency of my work & 4.43 & 0.693 \\
\hline & In general, using a new laboratory system is useful for my job & 4.36 & 0.832 \\
\hline \multirow{6}{*}{ Intention } & I intend to use the new laboratory system in the future when my profession is concerned & 4.39 & 0.798 \\
\hline & I will try to apply the changes that will occur in the new laboratory system & 4.29 & 0.652 \\
\hline & I intend to use the new laboratory system regularly in the near future & 4.32 & 0.672 \\
\hline & I will try to follow the innovations in the new laboratory system & 4.47 & 0.741 \\
\hline & I think that the use of new laboratory systems will increase in the future & 4.52 & 0.802 \\
\hline & I will strongly recommend the use of the new laboratory system to colleagues & 4.04 & 0.891 \\
\hline \multirow{13}{*}{$\begin{array}{c}\text { Perceived Ease } \\
\text { of Use }\end{array}$} & Using the new laboratory system makes work more complicated & 1.79 & 0.991 \\
\hline & I often make mistakes when using the new lab system & 2.23 & 0.972 \\
\hline & I find it boring to use the new laboratory system & 1.98 & 1.019 \\
\hline & I need more guidance when using the new lab system & 2.77 & 1.082 \\
\hline & I need to make a greater mental effort when using the new laboratory system & 2.54 & 1.127 \\
\hline & My mistakes are easier to find thanks to the new laboratory system & 4.14 & 1.002 \\
\hline & Thanks to the new laboratory system, I can easily do what I want about my lessons & 4.54 & 0.702 \\
\hline & The new laboratory system can lead to unexpected results & 2.63 & 0.921 \\
\hline & Using a new laboratory system makes me confused & 2.13 & 1.071 \\
\hline & The use of the new laboratory system is easy for me to understand & 3.92 & 0.809 \\
\hline & The new laboratory system helps to remind me of my duties & 3.98 & 0.831 \\
\hline & The new laboratory system guides me through my duties & 3.74 & 0.841 \\
\hline & In general, I find it easy to use the new laboratory system & 3.85 & 0.864 \\
\hline \multirow{4}{*}{ Attitude } & I am happy to use the new laboratory system & 3.86 & 0.701 \\
\hline & Using the new laboratory system makes me tense & 2.11 & 1.102 \\
\hline & I think that the use of the new laboratory system is detrimental & 2.41 & 1.156 \\
\hline & I find it unnecessary to use the new laboratory system & 1.93 & 1.029 \\
\hline \multirow{2}{*}{ Behavior } & I use the new laboratory system very often outside the campus & 3.81 & 0.914 \\
\hline & I use the new laboratory system very often inside the campus & 3.65 & 0.961 \\
\hline
\end{tabular}

When we look at the same way from the standpoint of attitude, the highest arithmetic average (3.86) stands out as "I am happy to use the new laboratory system".

Finally, the highest arithmetic mean (3.81) is the "I use the new laboratory system very often outside the campus" in the part of the behavior.

Relationships between the TAM components were examined utilizing a correlation analysis and the results are listed in Table 5.

Table 5. Correlation analysis results.

\begin{tabular}{ccccc}
\hline & Perceived Usefulness & Perceived Ease of Use & Attitude & Intention \\
\hline Perceived Usefulness & 1 & -0.121 & -0.165 & $0.743^{(* *)}$ \\
Perceived Ease of Use & -0.121 & 1 & $0.497^{(* *)}$ & 0.044 \\
Attitude & -0.165 & $0.497^{(* *)}$ & 0.131 \\
Intention & $0.743^{(* *)}$ & 0.044 & -0.013 & -0.131 \\
Behavior & 0.148 & -0.013 & -0.151 & 0.186 \\
\hline
\end{tabular}

$\left.{ }^{* *}\right)$ Significant with 0.01 error margin. 
When we look at the results of the correlation between variables, it is seen that positive and statistically significant relationships exist between perceived usefulness and perceived ease of use and attitude. Regression analysis was performed on the data obtained and the results are presented in Table 6.

Table 6. Regression analysis results.

\begin{tabular}{|c|c|c|c|c|c|c|c|c|c|c|c|c|}
\hline \multirow[b]{2}{*}{$\begin{array}{l}\text { Independent } \\
\text { Variables }\end{array}$} & \multicolumn{4}{|c|}{$\begin{array}{l}\text { Intent to Use Dependent Variable } \\
\text { Information Technologies }\end{array}$} & \multicolumn{4}{|c|}{$\begin{array}{l}\text { Attitude Toward the Use of Dependent } \\
\text { Variable Information Technologies }\end{array}$} & \multicolumn{4}{|c|}{$\begin{array}{c}\text { Actual Behavior for Use of } \\
\text { Dependent Variable Information } \\
\text { Technologies }\end{array}$} \\
\hline & $\beta$ & $\mathrm{P}$ & $\mathrm{F}$ & $\mathrm{R}^{2}$ & $\beta$ & $\mathrm{P}$ & $\mathrm{F}$ & $\mathrm{R}^{2}$ & $\beta$ & $\mathrm{P}$ & $\mathrm{F}$ & $\mathrm{R}^{2}$ \\
\hline $\begin{array}{l}\text { Perceived } \\
\text { Usefulness }\end{array}$ & 0.743 & 0.000 & 47.882 & 0.563 & -0.165 & 0.259 & 1.301 & 0.029 & & & & \\
\hline $\begin{array}{l}\text { Perceived Ease of } \\
\text { Use }\end{array}$ & & & & & 0.497 & 0.001 & 13.019 & 0.239 & & & & \\
\hline Attitude & 0.131 & 0.439 & 0.598 & 0.021 & & & & & & & & \\
\hline Intention & & & & & & & & & 0.186 & 0.228 & 1.486 & 0.033 \\
\hline Model & 0.781 & 0.000 & 29.971 & 0.619 & 0.511 & 0.003 & 6.921 & 0.254 & 0.186 & 0.228 & 1.486 & 0.033 \\
\hline
\end{tabular}

\section{Discussions and Suggestions}

$\mathrm{DE}$ is one of the areas that gain importance every day and draw attention to its advantages. Apart from the traditional advantages that the DE approach includes, there are also unresolved pending problems. One of the most important problems in distance learning is the laboratory requirement in education. Although extensive research has been carried out on educational outcomes of DE, to our knowledge a small number of comparative studies exist which specifically focus on technological improvements in DE. To address this need, studies have been carried out in the literature, but studies are generally local or course-dependent solutions. In this study, a laboratory system for DE students was developed in the area of information technologies. The study was evaluated with the questionnaires and assessments given to the students.

The effect of the newly developed laboratory system on student assignments was examined and details are presented in Table 3. According to the results obtained, the new laboratory system has a positive impact on the students' homework grades as per the weekly and final assignments given to the students. However, when the results of the first two weeks are examined, it is seen that there are very small differences between the students who use the new laboratory system and the assignments given in the traditional DE approach. It is considered that the main reason for this small difference is that the student is accustomed to the new laboratory system and that students are not given orientation to this area. Therefore, it is recommended that detailed training of the end-user is given to get full performance in the newly developed systems.

The dimensions that are effective in the formation of students' behavior towards the use of the system were examined. The following results were achieved.

1. It was concluded that the "perceived ease of use" did not affect the attitude towards the behavior.

2. The "perceived ease of use" by the students resulted in a positive attitude towards the behavior.

3. It was concluded that the "perceived usefulness" positively affected the intention to use.

4. It was concluded that behavioral attitudes towards the use of the system do not affect the behavioral intention.

5. The intention to use the developed system does not affect the behavior.

There are different frameworks and approaches used in the analysis of a product and its strategic position. One of the most frequently used is the SWOT analysis, which is short of "strengths, weaknesses, opportunities, and threats". SWOT analysis is used to appraise the strengths, weaknesses, opportunities, and threats involved in the Web-Based 
Remote Laboratory Implementation. Thanks to this analysis, it can be determined how the developed system is successful and perfect. The SWOT analysis of the system is as shown in Figure 6. In this part of the study, the result of the analysis was evaluated and addressed.

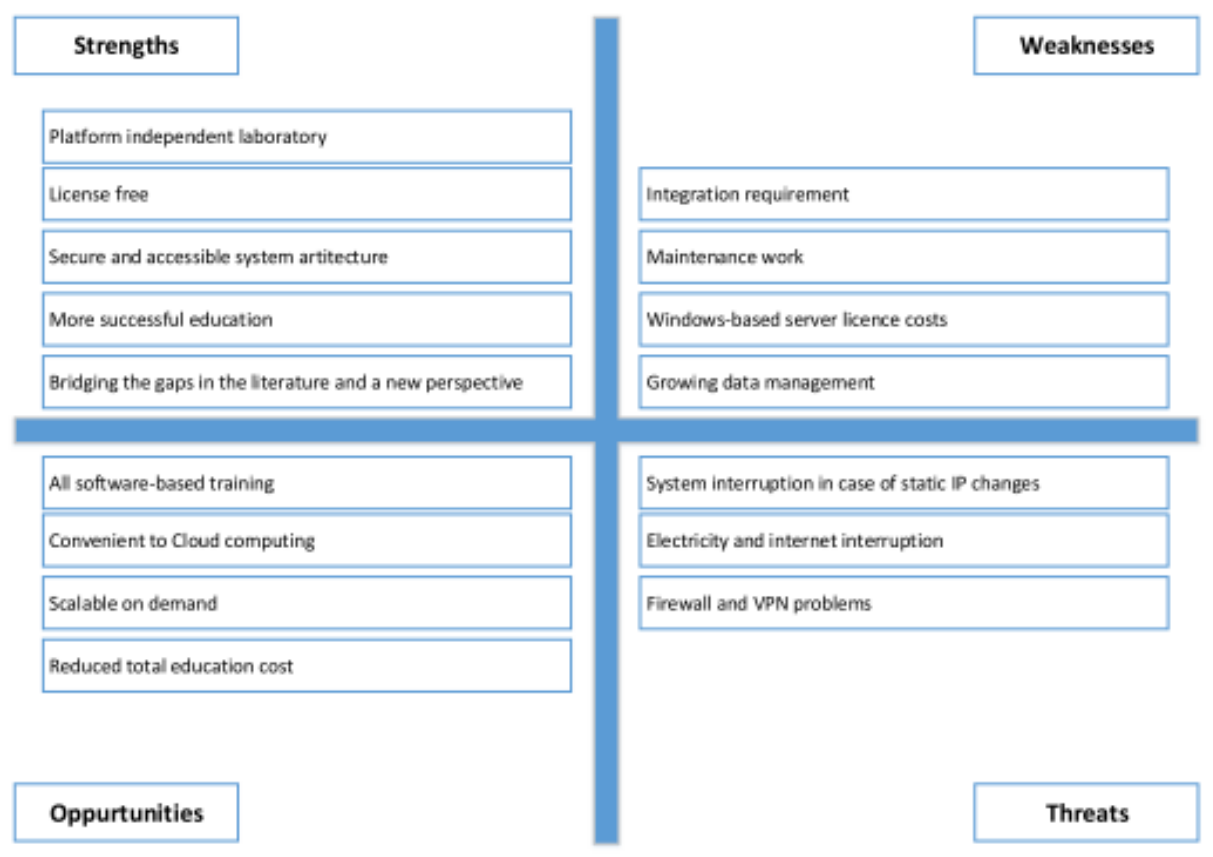

Figure 6. SWOT analysis.

\section{Conclusions}

Technology has become cheaper and widespread every day. This rapid development has also affected the field of education. As a result of this interaction, the concept of DE which has been used for years has come to the forefront. However, with the progress of digital concepts, instead of traditional DE methods, technology-focused DE methods have begun to be investigated and developed. In this study, a new platform-independent, technology-based laboratory system architecture for computers, smartphones, and tablets was developed for DE students of information technology to handle the problem of the lack of laboratories, the most important shortcoming in the traditional DE approach. With this system, it is aimed to increase the usability of the application in the traditional DE system.

In the 2017/2018 academic year, the software projects of the DE students in web technology and engineering have been used to test this new laboratory system. A total of 86 students in the class were randomly divided into two groups of 43 people. The same assignments were given to both groups and assignments were evaluated by independent instructors. The average score of 69.05 was obtained in the first group given traditional DE assignments. The average of the second group given assignment via the newly developed laboratory system was determined as 76.51. The mean score of the first group was 69.71 in the final assignment after the usage habits of the students have been formed and the average score of the second group using the developed new laboratory system was found to be 82.60 . A difference of $12.89 \%$ was observed between the two groups. It is also aimed to reveal the reasons for using the new laboratory system in the study through TAM. For this purpose, in the academic year of 2017/2018, field research was conducted for web programming courses of DE students in engineering and engineering fields. The results obtained from the TAM model are listed below.

Perceived use and intention trends for students' use of the system in the course of the course are quite high.

It is seen that the students' ease of use is perceived in the process of using the implemented laboratory for the lecture process and the attitude towards the behavior is affected 
positively. This means that if students can use the newly developed laboratory easily, they will show an attitude towards using these products. This finding is consistent with the results obtained by $[16,30]$.

The perceived use in the formation of students' behaviors towards the use of the newly developed laboratory in the course of study seems to positively influence the intention to use. This means that if the newly developed laboratory is used by the students that and they find it useful, they can be said to intend to use these products. This result is again consistent with [16].

The students' attitudes towards behavior during the newly developed laboratory concluded that perceived benefit has no effect on behavior and intention does not affect behavior.

In conclusion, the laboratory environment required for information technology and engineering education was improved by eliminating the deficiencies in the literature in this study. In this context, the developed information technology and the remote education laboratory applied in the field of engineering are bridging the gap in the literature.

Author Contributions: Conceptualization, E.E., A.E., M.Ü.; methodology, E.E., A.Ö.; software, A.E., A.Ö.; validation, A.E., E.E., and M.Ü.; formal analysis, E.E., and A.E.; investigation, E.E., and A.E.; resources, A.E.; writing—original draft preparation, E.E.; writing—review and editing, E.E., A.Ö., and M.Ü. All authors have read and agreed to the published version of the manuscript.

Funding: This work was partly supported by the Kırıkkale University Department of Scientific Research Projects (2016/107).

Institutional Review Board Statement: Not applicable.

Informed Consent Statement: Student consent was waived because real identities were not used.

Data Availability Statement: Data available on request due to restrictions e.g., privacy or ethical concerns. The data presented in this study are available on request from the authors.

Conflicts of Interest: The authors declare no conflict of interest. The funders had no role in the design of the study; in the collection, analyses, or interpretation of data, in the writing of the manuscript or in the decision to publish the results.

\section{References}

1. İbrahimoğlu, Z. Digital citizenship and education in Turkey: Experiences, the present and the future. In The Palgrave Handbook of Citizenship and Education; Springer: Cham, Switzerland, 2020; pp. 465-482.

2. Suárez, J.L.; García, S.; Herrera, F. A tutorial on distance metric learning: Mathematical foundations, algorithms, experimental analysis, prospects and challenges. Neurocomputing 2020. [CrossRef]

3. TSI Hanehalkı Bilişim Teknolojileri Kullanım Araştırması. 2020. Available online: https://data.tuik.gov.tr/Bulten/Index?p= Hanehalki-Bilisim-Teknolojileri-(BT)-Kullanim-Arastirmasi-2020-33679 (accessed on 22 January 2021).

4. Kurt, A.; Kuzu, A.; Dursun, Ö.; Güllepınar, F.; Gültekin, M. FATİH Projesinin Pilot Uygulama Sürecinin Değerlendirilmesi: Öğretmen Görüşleri. Öğretim Teknol. Öğretmen Eğitimi Derg. 2013, 1-23.

5. Forni, A.A. Gartner identifies the top 10 strategic technology trends for 2018. Gartner, 18 October 2016.

6. Riedling, A.M. Distance education: The technology-What you need to know to succeed, an overview. AACE J. 2020, 8, 13.

7. Qamar, S.Z.; Pervez, T.; Al-Kindi, M. Engineering education: Challenges, opportunities, and future trends. In Proceedings of the 16th IEOM Global Engineering Education: First GCC International Conference on Industrial Engineering and Operations Management (IEOM-2019), Riyadh, Saudi Arabia, 26-28 November 2019.

8. Shadiev, R.; Huang, Y.-M. Exploring the influence of technological support, cultural constructs, and social networks on online cross-cultural learning. Australas. J. Educ. Technol. 2020, 36, 104-118. [CrossRef]

9. MIT Distance Learning Courses. Available online: https://www.distancelearningportal.com/universities/11740/massachusettsinstitute-of-technology.html (accessed on 22 January 2021).

10. Harvard Online Learning. Available online: https:// online-learning.harvard.edu/ (accessed on 22 January 2021).

11. Docebo eLearning Market Trends and Forecast 2017-2021. Available online: https:/ /www.docebo.com/resource/elearningmarket-trends-and-forecast-2017-2021/ (accessed on 22 January 2021).

12. Guzmán, J.L.; Joseph, B. Web-based virtual lab for learning design, operation, control, and optimization of an anaerobic digestion process. J. Sci. Educ. Technol. 2020, 1-12. [CrossRef]

13. Burghardt, M.; Ferdinand, P.; Pfeiffer, A.; Reverberi, D.; Romagnoli, G. Integration of new technologies and alternative methods in laboratory-based scenarios. In Proceedings of the International Conference on Remote Engineering and Virtual Instrumentation, Athens, GA, USA, 26-28 February 2020; Springer: Cham, Switzerland, 2020; pp. 488-507. 
14. Al-Emran, M.; Mezhuyev, V.; Kamaludin, A. Technology acceptance model in M-learning context: A systematic review. Comput. Educ. 2018, 125, 389-412. [CrossRef]

15. Taherdoost, H. A review of technology acceptance and adoption models and theories. Procedia Manuf. 2018, $22,960-967$. [CrossRef]

16. Davis, F.D. Perceived usefulness, perceived ease of use, and user acceptance of information technology. MIS Q. 1989, 13, 319. [CrossRef]

17. Cîmpanu, C.; Lupu, R.-G.; Ungureanu, F.; Dumitriu, T. Virtual learning environments for never-ending learning: A survey. In Proceedings of the 16th International Scientific Conference eLearning and Software for Education, Bucharest, Romania, 30 April-1 May 2020.

18. Wicaksono, I.; Wasis, M. The effectiveness of virtual science teaching model (VS-TM) to improve student's scientific creativity and concept mastery on senior high school physics subject. J. Balt. Sci. Educ. 2017, 16, 549-561.

19. Nikolic, S.; Suesse, T.; Jovanovic, K.; Stanisavljevic, Z. Laboratory learning objectives measurement: Relationships between student evaluation scores and perceived learning. IEEE Trans. Educ. 2020, 1-9. [CrossRef]

20. Post, L.S.; Guo, P.; Saab, N.; Admiraal, W. Effects of remote labs on cognitive, behavioral, and affective learning outcomes in higher education. Comput. Educ. 2019, 140, 1-9. [CrossRef]

21. Halimi, W.; Salzmann, C.; Jamkojian, H.; Gillet, D. Enabling the automatic generation of user interfaces for remote laboratories. In Online Engineering and Internet of Things; Springer: Cham, Switzerland, 2018; pp. 778-793.

22. Fitzgerald, B. Drupal for Education and E-Learning; Packt Publishing Ltd.: Birmingham, UK, 2008.

23. Zhang, M.; Li, Y. Students' continuance intention to experience virtual and remote labs in engineering and scientific education. Int. J. Emerg. Technol. Learn. 2019, 14, 1-16. [CrossRef]

24. Ramya, M.V.; Purushothama, G.K.; Prakash, K.R. Design and implementation of IoT based remote laboratory for sensor experiments. Digital Library. 2020, 14, 227-238.

25. Harmening, J.T. Virtual private networks. In Computer and Information Security Handbook; Elsevier: Amsterdam, The Netherlands, 2013; pp. 855-867.

26. Osipov, V. Securing active directory. In Special Ops; Elsevier: Amsterdam, The Netherlands, 2003; pp. $243-302$.

27. Hannifin, D. Windows server 2008 R2 remote desktop services. In Microsoft Windows Server 2008 R2 Administrator's Reference: The Administrator's Essential Reference; Syngress: Rockland, MA, USA, 2010; pp. 353-398.

28. Reid, F. Network Programming in .NET; Elsevier: Amsterdam, The Netherlands, 2004; pp. 163-194.

29. Tian, W.; Zhao, Y. Load balance scheduling for cloud data centers. In Optimized Cloud Resource Management and Scheduling; Elsevier: Amsterdam, The Netherlands, 2015; pp. 95-114.

30. Cheng, J.M.-S.; Sheen, G.-J.; Lou, G.-C. Consumer acceptance of the internet as a channel of distribution in Taiwan-A channel function perspective. Technovation 2006, 26, 856-864. [CrossRef] 